\title{
Structural, Linear and Nonlinear Optical Properties of Zn@CdO Nanostructured Thin Films: A Quantitative Comparison With Dft
}

\section{Ziaul Raza Khan ( $\square$ zrazakhan05@gmail.com )}

University of Hail https://orcid.org/0000-0001-6449-911X

\section{Gandouzi}

University of Hail College of Sciences

Adullah S. Alshammari

University of Hail College of Sciences

M. Bouzidi

University of Hail College of Sciences

Mohd. Shkir

King Khalid University College of Science

\section{S. Alfaify}

King Khalid University College of Science

\section{Mansour Mohamed}

University of Hail College of Sciences

\section{Research Article}

Keywords: Zn-CdO nanostructured films, morphology, structural properties, optical properties, DFT investigation

Posted Date: February 24th, 2021

DOl: https://doi.org/10.21203/rs.3.rs-233259/v1

License: (c) (1) This work is licensed under a Creative Commons Attribution 4.0 International License. Read Full License 


\section{Structural, linear and nonlinear optical properties of $\mathrm{Zn} @ \mathrm{CdO}$ nanostructured thin films: A quantitative comparison with DFT}

\section{Z. R. Khan ${ }^{a}$, M. Gandouzi ${ }^{a}$, Abdullah S. Alshammari ${ }^{a}$, M. Bouzidi, ${ }^{a, c}$,Mohd. Shkir ${ }^{b}$, S. Alfaify, Mansour Mohamed ${ }^{a, d}$}

${ }^{a}$ Department of Physics, Faculty of Science, University of Ha'il, P.O. Box 2440, Ha'il, Saudi Arabia

${ }^{b}$ Advanced functional materials and optoelectronics laboratory (AFMOL), Department of Physics, Faculty of Science, King Khalid University, P.O. Box 9004, Abha, Saudi Arabia. ${ }^{c}$ Université de Monastir, Faculté des Sciences, Unité de recherche sur les HétéroEpitaxies et Applications (URHEA), 5000 Monastir, Tunisia

${ }^{d}$ Department of Physics, Faculty of Science, Assiut University, Assiut 71516, Egypt

\section{Abstract}

This paper presents experimental and density functional theory (DFT) investigations of $\mathrm{Zn}$ doping role in the $\mathrm{Zn} @ \mathrm{CdO}$ ternary system. $\mathrm{Zn}$ doped $\mathrm{CdO}$ nanostructures with different $\mathrm{Zn}$ concentrations were successfully casted on glass substrates by sol-gel spin coating method. Cubic Zn@CdO structured ternary alloyed nanostructures thin films with $0.0 \%, 1.0 \%, 2.0 \%$ and $3.0 \%$ wt. $\mathrm{Zn}$ concentrations were obtained. An enhancement in the lateral growth of $\mathrm{CdO}$ cauliflower-like nanostructures was observed after $\mathrm{Zn}$ addition which leads to a 2D growth of nanostructured films with improved continuity. The effect of $\mathrm{Zn}$ doping on the linear optical parameters such as the optical band gap, the absorption index and the refractive index were also investigated. A remarkable blue shift in the band edge was observed as $\mathrm{Zn}$ is incorporated into the $\mathrm{CdO}$ matrix. In addition, the third order nonlinear optical parameters $\chi^{(3)}$ and $n_{2}$ were calculated and found to be about $2.89 \times 10^{-12}$ $-4.33 \times 10^{-14} e s u$ and $2.89 \times 10^{-12}-4.33 \times 10^{-14} e s u$; respectively. A density functional theory (DFT) based Wien2k package was utilized to theoretically investigate the lattice parameters, the electronic structure, the absorption index and the refractive index of the $\mathrm{Zn} @ \mathrm{CdO}$ ternary nanoalloys. The role of $\mathrm{Zn}$ doping on the aforesaid properties was theoretically investigated for $3.125 \%, 6.25 \%, 12.5 \%$ and $25 \% \mathrm{Zn}$ doping concentrations 
and was compared with the experimentally determined parameters. The combined theoretical and experimental investigations presented herein along with the detailed discussion of the obtained findings would provide a deep understanding of the optoelectronic behavior of the $\mathrm{Zn}$ doped $\mathrm{CdO}$ nanostructured films as well as their suitability for devices applications.

Key words: Zn-CdO nanostructured films; morphology; structural properties; optical properties; DFT investigation

*Corresponding author email ID: zrazakhan05@gmail.com

\section{Introduction}

Metal oxide based 2-D semiconducting nanostructures have demonstrated a high potential for many applications in the field of optoelectronics and gas sensing devices. $\mathrm{CdO}$ is one of the prominent II-VI group metal oxide semiconductor with a cubic structure and a direct band gap of about $2.20 \mathrm{eV}$. It also shows a narrow indirect band gap in the energy region below $1 \mathrm{eV}$ [1]. Moreover, $\mathrm{CdO}$ has an excellent conductivity and suitable transmission in the uv-vis region. It exhibits n-type conductivity with native oxygen vacancies $\left(V_{o}\right)$ and $C d$ interstitials $\left(C d_{i}\right)$ which provide an easy way to alter the electronic structure of $\mathrm{CdO}$ by various metallic elements doping. This alteration in the electronic structure of $\mathrm{CdO}$ helps in the exploitation of $\mathrm{CdO}$ possible uses in various devices applications such as solar cells, detectors, transistors and sensors [2-10]. In addition, $\mathrm{CdO}$ exhibits significant third order nonlinear optical properties which are very useful for optical limiting and laser controlled devices applications [11-12]. To enhance the linear, the third order nonlinear optical and the electrical properties of the $\mathrm{CdO}$ films, the incorporation of a suitable external impurity into the $\mathrm{CdO}$ matrix is essential. Recently, $\mathrm{CdO}$ films have been fabricated with various doping elements such as $\mathrm{Al}, \mathrm{Ag}$, 
$\mathrm{Zn}, \mathrm{Gd}, \mathrm{Mn}$ and $\operatorname{Pr}[13-17]$. On the other hand, the facile and cost effective fabrications of the $\mathrm{CdO}$ films via sol-gel spin coating, chemical bath deposition and spray pyrolysis methods have attracted immense interests due to the low production cost in addition to the possible unique physical properties of the grown nanostructures [18-20]. In the current work, a sol-gel spin coating technique was employed to develop the $\mathrm{Zn} @ \mathrm{CdO}$ nanostructured thin films with different $\mathrm{Zn}$ doping concentrations. In the light of aforesaid significance of $\mathrm{CdO}$, the investigation of the experimentally developed nanostructured films properties and their electronic behavior is very essential. Moreover, the comparison of the obtained experimental results with those acquired from density functional theory (DFT) studies would provide a better understanding of this material system and help to achieve a better controlling of the band gap variation in the $\mathrm{CdO}$ based nanostructures. The good control of the $\mathrm{CdO}$ band gap and the related optical and electronic properties would surly strengthen further the candidature of the $\mathrm{CdO}$ films for the above mentioned as well as future novel applications. Theoretical investigations of CdO have been reported by various researchers using DFT studies. S. A. Khan et al have investigated electronic structure variation of bulk $\mathrm{CdO}$ when transformed into nanosheet [21]. M. Durandurdu has investigated the $\mathrm{CdO}$ electronic structure properties via DFT theory and has reported on their suitability for electronic device applications [22]. R. Miloua et. al. have studied $\mathrm{Cd}_{1-\mathrm{x}} \mathrm{Zn}_{\mathrm{x}} \mathrm{O}$ alloys using wien2k via DFT approach. They have found in their study a clear phase separation with $\mathrm{Zn}$ doping [23]. However, structural, electronic and optical properties investigations of $\mathrm{Zn} @ \mathrm{CdO}$ alloys via BeckeJohson(mBJ), with local gradient generalized approximation (GGA) found very rare in literature. 
The current study reports the investigation of pure and 1, 2 and 3 wt.\% $\mathrm{Zn}$ doped $\mathrm{CdO}$ nanostructured thin films fabricated on glass substrates with a cauliflower morphology via a sol-gel spin coating method. The structural, linear optical and nonlinear optical properties of the films were estimated and discussed in correlation with the $\mathrm{Zn}$ doping concentrations. In addition, the reported experimental results are combined with detailed theoretical investigations of the structural and electronic structure of the $\mathrm{Zn}$ doped CdO films which were carried out using Wien2k code within framework of DFT. The combined experimental and theoretical investigations in the present work provides comprehensive information on the $\mathrm{Zn} @ \mathrm{CdO}$ nanostructured thin films and would be very useful for the next generation $\mathrm{CdO} 2 \mathrm{D}$-nanostructures based optoelectronic devices.

\section{Experimental and theoretical details}

\subsection{Experimental details and characterization techniques}

Zn@CdO thin films with cauliflower morphology were developed successfully via facile and cost effective sol-gel spin coating method with 1, 2 and 3 wt.\% $\mathrm{Zn}$ doping concentrations. Highly pure cadmium acetate and zinc sulfate heptahydrate (from Sigma Aldrich Company) were used as cadmium and zinc sources. To synthesize Zn@CdO sols for film casting, $0.75 \mathrm{M}$ solution of cadmium acetate $(1.99 \mathrm{gm})$ in $10 \mathrm{ml} 2$ methoxyethanol solvent was prepared separately in four beakers and stirred at $40{ }^{\circ} \mathrm{C}$ for 1 hr. After that, zinc sulphate heptahydrate was added to the prepared solution at different weight percentages $0,1,2$ and $3 \mathrm{wt} . \%$ corresponding mass is $0 \mathrm{mg}, 19.99 \mathrm{mg}, 39.98 \mathrm{mg}$, $59.97 \mathrm{mg}$ and with vigorous stirring for $1 \mathrm{hr}$ at same temperature. Monoethanolamine was also added slowly to enhance the homogeneity and the stability of the solution. Then, 
the as prepared solutions were used to fabricate uniform nanostructured thin films on precleaned glass substrates via spin coating at $1500 \mathrm{rpm}$ for $30 \mathrm{~s}$. After the coating, the prepared films were placed on a hot plate at $140{ }^{\circ} \mathrm{C}$ for $3 \mathrm{~min}$ and the same process was repeated 10 times. The prepared films were then left, after completing all the deposition steps, on a hot plate at $150{ }^{\circ} \mathrm{C}$ for $10 \mathrm{~min}$ to remove any residual solvents from the samples. Finally, the samples were annealed in air in a furnace at $450{ }^{\circ} \mathrm{C}$ for 90 minutes.

The structural information of the grown films was obtained using Shimadzu X-ray diffractometer $\left(\mathrm{X}-600\right.$, Japan) with $\mathrm{Cu}-\mathrm{K} \alpha$ radiation in the angular range $\sim 10^{\circ}-80^{\circ}$. The surface morphological studies of the films were investigated by scanning electron microscope (FEI Quanta 250). The transmittance, absorbance and reflectance spectra of the films in the range 190-2500 $\mathrm{nm}$ were recorded using a UV-Vis-Nir spectrophotometer (LAMBDA 1050+ PerkinElmer).

\subsection{Theoretical details}

The theoretical investigation of the structural, electronic and optical properties was conducted by density functional theory (DFT) implemented in WIEN2k code [2425]. This approach yields reliable results for structural, electronic and optical properties of various solids as shown in several works. The study was performed with the full potential linearized augmented plane wave (FLAPW) method which has been shown to have a remarkable accuracy to study the electronic structure and the optical properties of the crystalline materials [26]. The gradient generalized approximation (GGA) combined with the modified Becke-Johnson exchange potential $(\mathrm{mBJ})$ was used to investigate the optoelectronic properties of $\mathrm{CdO}$ binary and $\mathrm{ZnCdO}$ alloys. The parameter $\mathrm{R}_{\mathrm{MT}} \cdot \mathrm{K}_{\mathrm{MAX}}$ is

chosen as 8 . Here $\mathrm{R}_{\mathrm{MT}}$ denotes the atomic sphere radius and $\mathrm{K}_{\mathrm{MAX}}$ is the max modulus for 
the reciprocal lattice vectors. The spherical harmonics overlapping muffin-tin (MT) spheres are expanded up to $l_{\max }=10$. The muffin-tin radii $R_{M T}$ are chosen to have the following values 2.6, 2.2 and 1.8 Bohr for $\mathrm{Cd}, \mathrm{Zn}$ and $\mathrm{O}$ respectively. To turn the structural optimization and the optoelectronic properties we construct four configurations supercell $2 \times 2 \times 2,2 \times 2 \times 1,2 \times 1 \times 1$, and $1 \times 1 \times 1$ containing $64,32,16$, and 8 atoms respectively in which $\mathrm{Zn}$ atom substitutes $\mathrm{Cd}$ in $\mathrm{Cd}_{1-\mathrm{x}} \mathrm{Zn}_{\mathrm{x}} \mathrm{O}$ ternary alloys.

Furthermore, the lattice parameters and the electronic properties are investigated with a specific number of $\mathrm{k}$ points in the irreducible Brillouin zone (IBZ) [27]. Here the values of $\mathrm{k}$ is equal to 63 for $x=\frac{1}{32}, 87$ for $x=\frac{1}{16}, 108$ for $x=\frac{1}{8}$, and 125 for $x=\frac{1}{4}$. Finally, all the structural calculation of $\mathrm{Cd}_{1-\mathrm{x}} \mathrm{Zn}_{\mathrm{x}} \mathrm{O}$ ternary alloys, and $\mathrm{CdO}$ binary were performed in rock salt structure.

\subsection{Results and discussion}

\subsection{Structural investigations}

The effect of $\mathrm{Zn}$ doping on the structural properties of $\mathrm{CdO}$ nanostructured thin films was investigated by XRD patterns which are presented in Fig.1. All the prepared films with the different compositions show a characteristics diffraction peak at $2 \theta$ angle $\sim 33.08$ along (111) plane which is in a good agreement with the reported data of the cubic $\mathrm{CdO}$ structure (JCPDS \# 05-0640) [28-29]. An interesting effect of Zn doping on the structural properties of the doped films can also be noticed from Fig.1, which is the degradations of the films crystallinity as $\mathrm{Zn}$ element is added into the $\mathrm{CdO}$ matrix. Debye Scherer's empirical relation ( $D_{\text {avg }}=\frac{0.9 \lambda}{\beta \cos \theta}$ ) was used to obtain the crystallite sizes of the films which were found to be in range $12-23 \mathrm{~nm}$ [30]. The lattice parameter (a), the volume of 
the unit cell $(\mathrm{V})$, the dislocation density $\left(\delta_{\text {ave }}\right)$ and the strain $\left(\varepsilon_{\text {ave }}\right)$ were calculated using the relations: $d=\frac{a}{\sqrt{h^{2}+k^{2}+l^{2}}}, \delta_{\text {avg }}=\frac{1}{D^{2}}, \quad \varepsilon_{\text {ave }}=\frac{\beta \cot \theta}{4} \quad$ [31-34]. The obtained structural parameters of the films are presented in Table 1.

Table1: structural parameters of $\mathrm{Zn@CdO} \mathrm{nanostructured} \mathrm{films.}$

\begin{tabular}{|c|l|l|l|l|c|c|}
\hline $\begin{array}{l}\text { Samples } \\
(\text { Ag@CdO) }\end{array}$ & $\mathrm{d}_{111}$ & $\begin{array}{l}\mathrm{a}=\mathrm{b}=\mathrm{c} \\
(\AA)\end{array}$ & $\mathrm{V}(\AA)^{3}$ & $\begin{array}{l}D_{\text {ave }} \\
(\mathrm{nm})\end{array}$ & $\begin{array}{l}\delta_{\text {ave }}\left(\mathrm{nm}^{-2}\right) \\
\times 10^{-2}\end{array}$ & $\begin{array}{l}\varepsilon_{\text {ave }} \\
\times 10^{-2}\end{array}$ \\
\hline JCPDS \# 05-0640 & 2.7120 & 4.6953 & 103.5100 & ---- & ---- & ---- \\
\hline 0.0 wt.\% & 2.7242 & 4.7183 & 105.040 & 12.68 & 0.6219 & 0.4312 \\
\hline 1.0 wt.\% & 2.7137 & 4.7001 & 103.829 & 15.68 & 0.4067 & 0.3269 \\
\hline 2.0 wt.\% & 2.6833 & 4.6474 & 100.376 & 17.23 & 0.3368 & 0.4777 \\
\hline 3.0 wt.\% & 2.7072 & 4.6889 & 103.087 & 23.42 & 0.1823 & 0.7825 \\
\hline
\end{tabular}

\subsection{Morphological Studies}

The surface morphologies of the films with the different compositions are shown in Fig. 2(a-d). It can be observed clearly from Fig. 3(a) that the pure $\mathrm{CdO}$ film contains cauliflower-like nanostructures. $\mathrm{As} \mathrm{Zn}$ is incorporated into the $\mathrm{CdO}$ cauliflower nanostructures, the morphology of the films remarkably changes. It can be concluded that the increase in $\mathrm{Zn}$ concentrations leads to the merging of the cauliflower nanostructure and a well coverage of the substrates with a $\mathrm{CdO}$ film of a sea waves-like morphology. This suggests that the presence of the $\mathrm{Zn}$ enhances the $2 \mathrm{D}$ growth of the $\mathrm{CdO}$ based film. The growth in the case of the pure $\mathrm{CdO}$ samples takes place in both lateral and vertical directions at the same rate. However, it looks that in the case of the doped samples the lateral growth becomes dominant which promotes the 2D growth and hence results in the formation of a film instead of individual nanostructures. These observations can be also linked to the obtained structural parameters namely the variation in the strain values upon Zn doping. The overall increase in the strain values can be explained by the enhancement of the $2 \mathrm{D}$ growth in the samples after $\mathrm{Zn}$ addition. 


\subsection{Uv-Vis-Nir spectroscopic investigations}

Fig. 3(a-c) represents the absorbance, transmittance and reflectance spectra of the $\mathrm{Zn} @ \mathrm{CdO}$ nanostructured thin films in Uv-vis-NIR region. The optical parameters of the prepared films such as the optical band gap, the absorption index $(k)$ and the refractive index $(n)$ were estimated from these spectra. Fig. 3(a) shows the absorption edge at 520 $\mathrm{nm}$ which is related to the band to band transition of the $\mathrm{CdO}$ material. However, exceptional behavior of the absorbance of the pure $\mathrm{CdO}$ films was recorded, may be due to the cauliflower morphology of the films, and is entirely different in comparison with the $\mathrm{Zn}$ doped $\mathrm{CdO}$ films. Unlike the doped films, the pure ones show a strong absorbance at $1400 \mathrm{~nm}$. Fig. 3(b) shows a significant improvement in the transmittance of the films in the visible to the NIR region upon incorporation of $\mathrm{Zn}$ into the $\mathrm{CdO}$ films. Fig. 3(c) shows the reflectance spectra of the pure and $\mathrm{Zn}$ doped $\mathrm{CdO}$ thin films. The reflectance of the films in region $250-500 \mathrm{~nm}$ is very low as observed and increases in region 500$2500 \mathrm{~nm}$.

The optical band gaps of the films were calculated using Tauc relation $(\alpha h v)=A\left(h v-E_{g}\right)^{m}$, where $\alpha, v, h, E_{g}, m$ and $A$ stand for absorption coefficient, photon frequency, Planck constant, optical band gap, transition type and transition constant [35]. The optical band gap values of the films were extracted from the plots in Fig. 4(a), and were found in to be in the order of $2.07 \mathrm{eV}, 2.39 \mathrm{eV}, 2.60 \mathrm{eV}$ and $2.47 \mathrm{eV}$ for pure, 1 wt.\% $\mathrm{Zn}, 2 \mathrm{wt} . \% \mathrm{Zn}$ and $3 \mathrm{wt} . \% \mathrm{Zn}$; respectively. The optical band gap of the films increases with the increase in $\mathrm{Zn}$ doping concentrations. Similar values of the optical band gap of sol-gel synthesized CdO films have been reported earlier [36-37]. 
The relation $k=\frac{\alpha \lambda}{4 \pi}$, was used to estimate the extinction coefficient where $\alpha$ denotes the absorption coefficients and $\lambda$ denotes the wavelength [38]. Fig. 4(b) illustrates the absorption index of the pure and $\mathrm{Zn}$ doped $\mathrm{CdO}$ nanostructured films. The values of $k$ were obtained in the range of 0.01-0.21. Fresnel relation $n=\frac{(1+R)}{(1-R)}+\sqrt{\frac{4 R}{(1-R)^{2}}-k^{2}}$ was used to determine the refractive index of the pure and $\mathrm{Zn}$ doped CdO nanostructured films in the spectral range 190-2500 $\mathrm{nm}$ [39]. The refractive index values $n$ of the films was found to be in the range of 1.05-2.36. A significant effect of $\mathrm{Zn}$ doping on the refractive index of the films can be noticed from Fig. 4(c), as $\mathrm{Zn}$ atoms replaces $\mathrm{Cd}$ atoms in the $\mathrm{CdO}$ matrix, the refractive indexes of films are remarkably enhanced in the region 500-2500 $\mathrm{nm}$. These results indicate that these films can be good contenders for optoelectronic applications.

The real $\left(\varepsilon_{1}\right)$ and imaginary $\left(\varepsilon_{2}\right)$ parts of the optical dielectric constant of a material reflect the electronic transition finger prints of that material as a function of the photon energy. The relations, $\varepsilon_{1}=n^{2}-k^{2}$ and $\varepsilon_{2}=2 n k$ was used to determine the real and the imaginary parts of the optical dielectric constant [40-42]. Fig. 5(a) shows the real part of the dielectric constant where the values of $\varepsilon_{1}$ were recorded in range of $1.22-5.5$. $\mathrm{Zn}$ doped films reveal a noticeable enhancement in $\varepsilon_{1}$ in the energy range $0.5-2.0 \mathrm{eV}$. The imaginary part $\varepsilon_{2}$ is shown in Fig. 5(b). The values of $\varepsilon_{2}$ were found to be in the range of 0.04-0.53. It can be seen that $\varepsilon_{2}$ decreases in the photon energy range $0.75-2.75 \mathrm{eV}$ as $\mathrm{Zn}$ doping concentrations increase. The reduction in the value of $\varepsilon_{2}$ with the increase in the Zn doping concentrations indicates the minimization of defects in the $\mathrm{Zn} @ \mathrm{CdO}$ films.

\subsection{Nonlinear optical properties of the $\mathrm{Zn} @ \mathrm{CdO}$ nanostructured film}


The third order nonlinearity plays a significant role in the advancement of the next generation photonics devices. The third order nonlinearity occurs in materials when an intense ray of light passes through the materials. For example, the nonlinear refractive index $\mathrm{n}_{2}$ varies with the change in the light intensity. When films are exposed to an intense light, electronic polarization causes a nonlinear optical behavior of the material with the electric field. This nonlinear electronic polarization $P_{N L}$ is expressed by the following relation [43]:

$P_{N L}=\chi^{(2)} E^{2}+\chi^{(3)} E^{3}+$

Where $\chi^{(2)}$ and $\chi^{(3)}$ stand for the second and third order nonlinear optical susceptibilities, respectively. A general relation of the refractive index as a function of the wavelength can be expressed as: $n(\lambda)=n_{o}(\lambda)+n_{2}\left(E^{2}\right)$ where $\left(E^{2}\right)$ stand for the mean square electric field. In this equation the linear refractive index $n_{o}(\lambda)>>n_{2}(\lambda)$ and by considering this approximation in refractive index equation, it becomes $n(\lambda)=n_{o}(\lambda)$. The linear optical susceptibility $\chi^{(1)}$ of a medium is related to the refractive index via the relation $\chi^{(1)}=\frac{\left(n^{2}-1\right)}{4 \pi}$ [44]. Miller's generalized rule also gives the opportunity to roughly estimate the third order nonlinear optical susceptibility $\chi^{(3)}$ of a medium through the relation $\chi^{(3)}=\mathrm{A}\left(\chi^{(1)}\right)^{4}$, where $\mathrm{A}$ is a constant $\left(\sim 1.7 \times 10^{-10} \mathrm{esu}\right)$ and has the same value for all materials. The nonlinear refractive index $n_{2}$ of the films were calculated using the relation $n^{(2)}=\frac{12 \pi \chi^{(3)}}{n_{o}}$, which is a combination of Miller generalized rule and $n_{o}$ [45]. The calculated $\chi^{(1)}, \chi^{(3)}$ and $n_{2}$ of the $\mathrm{Zn} @ \mathrm{CdO}$ nanostructured thin films are shown in Fig. 6(a-c). Fig. 6(a) shows a significant enhancement in the first order linear optical susceptibility of the films with increasing $\mathrm{Zn}$ doping concentrations. The values of $\chi^{(1)}$ 
were found to be in the range $0.016-0.36$. Moreover, the values of $\chi^{(3)}$ were estimated to be in the range of $2.89 \times 10^{-12}-4.33 \times 10^{-14}$ esu for all the films with the different compositions which reveals a remarkable improvement in the $\chi^{(3)}$ values as compare to the earlier reported work on $\mathrm{Zn}$ doped $\mathrm{CdO}$ system [11]. The nonlinear refractive index $n_{2}$ of the films was found in to be in the range $2.89 \times 10^{-12}-4.33 \times 10^{-14}$ esu. The third order nonlinear parameters values suggest that the $\mathrm{Zn} @ \mathrm{CdO}$ films have good nonlinear optical properties and can be potential candidates for next generation photonic devices.

\subsection{DFT investigations of $\mathrm{Zn@CdO} \mathrm{alloys}$}

The structural parameters of the $\mathrm{Zn@CdO}$ alloys were estimated for the optimized structure with different compositions by the minimization of energy versus the cell volume. The cubic rock salt crystal structures of $\mathrm{Cd}_{1-\mathrm{x}} \mathrm{Zn}_{\mathrm{x}} \mathrm{O}$ with $3.125 \%$ and $6.25 \% \mathrm{Zn}$ doped supercell are shown in Fig.7 (a-b). Fig.8 also illustrates the plot of the total energy versus the cell volume for $3.125 \% \mathrm{Zn}$ doped $\mathrm{CdO}$ alloys. The lattice parameters of the pure $\mathrm{CdO}$ were found to be in range 4.788-4.7044 $\AA$. However, the lattice parameter of the sample doped with $12.5 \% \mathrm{Zn}$ was found to be about $5.231 \AA$ which reveals a significant increase in lattice parameter after doping. Moreover, the calculated lattice parameters were found to be slightly larger than those experimentally obtained. The lattice parameters of the nanostructured alloyed films also decrease with increasing $\mathrm{Zn}$ doping concentrations in both sides of the current investigations which indicates a good agreement between the experimental and theoretical findings regarding the behavior of the lattice constants of $\mathrm{CdO}$ films with $\mathrm{Zn}$ doping. R. Miloua et. al. have investigated the structural properties of $\mathrm{Zn} @ \mathrm{CdO}$ alloyed films with LDA approximation and have found similar behavior of the lattice parameters with the increase in $\mathrm{Zn}$ concentrations. 
However, they have reported lesser lattice parameters value than the present work [23]. Fig. 9 shows the comparative behavior of the lattice parameters experimental and theoretical values as a function of $\mathrm{Zn}$ doping concentrations.

The electronic structure variation with the $\mathrm{Zn}$ doping in the cubic $\mathrm{CdO}$ alloys was investigated through the total density of states (TDOS) within the energy interval from $\mathrm{E}_{\mathrm{F}},-8.0$ and $8.0 \mathrm{eV}$ and is presented in Fig.10 (a-b). As can be seen from Fig. 10(a), the top of the valence band from -2.0 to $1.0 \mathrm{eV}$ is mainly arises due to the contribution of the O-p state and reveals minor contribution of the Cd-d state. Furthermore, the conduction band from 2.0-6.0 eV arises due to the overlapping of the O-p, the O-s and the Cd-p states and the core bands are mainly consisting of the O-p and the Cd-d state. The peaks of core bands are centered at 6-7 eV [46]. Fig.10 (b) shows the 3.125\% Zn doped CdO system TDOS. With the incorporation of $\mathrm{Zn}$ into the $\mathrm{CdO}$ matrix, the role of $\mathrm{Zn}-4 \mathrm{~s}$ can be observed clearly. A significant shifting in the bottom of conduction band occurs and hence an increase in the band gap of the $\mathrm{CdO}$ after $\mathrm{Zn}$ doping is observed. A comparable effect on TDOS can be seen clearly after Zn incorporation from TDOS plots of both systems, a new bunch of TDOS arises at $-4.72 \mathrm{eV}$, which is mainly due to the $\mathrm{Zn}-\mathrm{d}$ state.

The band structures of the $\mathrm{Zn} @ \mathrm{CdO}$ alloys with $3.125 \%, 6.25 \%, 12.5 \%$ and $25 \%$ Zn doping concentrations are illustrated in Fig.11 (a-e). The calculated values of the band gap for the $3.125 \%, 6.25 \%, 12.5 \%$ and $25 \% \mathrm{Zn}$ doped samples were obtained as $1.47 \mathrm{eV}$, 1.69, 1.69, 1.03 and $1.83 \mathrm{eV}$; respectively. Interesting changes can be seen from Fig.11 (a-e), where the pure $\mathrm{CdO}$ sample shows an indirect nature of the band gap while the $\mathrm{Zn} @ \mathrm{CdO}$ samples reveal a direct nature of the band gap. Additionally, these theoretical findings agree well with the experimentally obtained results regarding the band gap 
nature from Fig. 4(a). Tauc plot for the pure $\mathrm{CdO}$ films shows a band gap of $2.07 \mathrm{eV}$ along with a $0.85 \mathrm{eV}$ indirect transition. The calculated band gap of the films increases by about $25 \%$ as a function of $\mathrm{Zn}$ concentrations. The increase in the band gap is due to the upward shifting of the bottom of the conduction band along the $\Gamma$ point as observed from Fig. 11(b-c) for the $\mathrm{CdO}$ samples doped with $3.125 \%$ and $6.25 \% \mathrm{Zn}$. However, the sample doped with $12.5 \% \mathrm{Zn}$ concentration demonstrates a different band gap behavior. At this concentration, $12.5 \% \mathrm{Zn}$, the band gap value significantly increases and then decreases with further increase in $\mathrm{Zn}$ concentration. Such variation in the band gap might be due to the phase transition of the $\mathrm{CdO}$ structure from cubic to hexagonal. Further investigations especially on the experimental side, at high doping concentrations, is currently ongoing in order to determine the reason of such observed behavior of the band gap and will be reported in the near future.

The optical properties of the $\mathrm{Zn} @ \mathrm{CdO}$ ternary alloys with various $\mathrm{Zn}$ concentrations were obtained using the complex function of the optical dielectric constant $\varepsilon(\omega)=\varepsilon_{1}(\omega)+i \varepsilon_{2}(\omega)$. The imaginary part of the optical dielectric constant $\varepsilon_{2}(\omega)$ is described via the direct transition [47-50]:

$\varepsilon_{2}(\omega)=\frac{4 \pi e^{2}}{m^{2} \omega^{2}} \sum_{i j} \int\left\langle k_{i}|p| k_{j}\right\rangle^{2} f\left(k_{i}\right)\left(1-f\left(k_{j}\right)\right) \delta \times\left(E_{k i}-E_{k j}-h \omega\right) d^{3} k$

Here $p$ is symbolized for the dipole matrix. The conduction and valence band wave functions of $i^{\text {th }}$ and $j^{t h}$ eigenvalues are symbolized $\left|k_{i}\right\rangle,\left|k_{j}\right\rangle$ for the crystal momentum $k$.

The real part of the optical dielectric constant $\varepsilon_{1}(\omega)$ was deduced from Kramers-Kronig relations [51]:

$\varepsilon_{1}(\omega)=1+\frac{2}{\pi} P \int_{0}^{\infty} \frac{\omega^{\prime} \varepsilon_{2}\left(\omega^{\prime}\right)}{\omega^{\prime 2}-\omega^{2}} d \omega$ 
The real and imaginary parts of the optical dielectric constant are the sources of the optical parameters of materials. Here, $\varepsilon_{1}(\omega)$ and $\varepsilon_{2}(\omega)$ are used to calculate the extinction coefficient $(k)$, the refractive index $(n)$ and the absorption coefficient $(\alpha)$. Fig.12 (a-b) presents the calculated real and imaginary parts of the optical dielectric constant in the range of 1-10 eV. Fig. 12(a) shows peaks at 2-3 eV range which are related to the interband transition of the $\mathrm{Zn} @ \mathrm{CdO}$ ternary alloys. An interesting change can be observed with the $\mathrm{Zn}$ incorporation in the $\mathrm{CdO}$ system that is a clear blue shift with increasing $\mathrm{Zn}$ doping concentrations. However, the $12.5 \% \mathrm{Zn}$ doped $\mathrm{CdO}$ sample shows anomalous behavior which supports the previous observation regarding the occurrence of some phase changes in structure of $\mathrm{CdO}$ at this $\mathrm{Zn}$ concentration. The static dielectric constant $\varepsilon_{1}(\omega=0)$ values of the samples were found to be in the range 3.2-3.4 and slightly decreases with the increase in $\mathrm{Zn}$ doping concentrations. Moreover, the $12.5 \% \mathrm{Zn}$ doped sample shows an enhancement in the static dielectric constant in comparison to other samples. Fig.12 (b) shows that the band edge of the films is around 2.2-2.5 eV which is very close to the experimentally obtained values of band gap. The DFT investigation of the films reveals a blue shift in band edge as $\mathrm{Zn}$ doping concentrations increase in $\mathrm{CdO}$ system indicating a shift of the bottom of the conduction band to the higher energy levels. A similar behavior of the $\mathrm{Zn} @ \mathrm{CdO}$ alloyed systems was confirmed through the experimental investigation of the electronic structure. Fig. 13(a) depicts the calculated absorption index $(k)$ of the $\mathrm{Zn} @ \mathrm{CdO}$ alloys with the different $\mathrm{Zn}$ doping concentrations. The plots of the calculated absorption index show that the band edge is in the similar range as estimated from the Uv-visible-nir spectroscopy. In the higher energy region from 3-10 eV, the absorption index increases. The calculated values of $k$ were found in to 
be in the range of 0.01-1.0. A significant blue shift was also observed in band edge as found experimentally. The calculated refractive index $n$ of the $\mathrm{Zn} @ \mathrm{CdO}$ alloys is depicted in Fig.13 (b) in the range of 0-10 eV. The refractive index of the alloys increases with the increase in the photon energy up to $3 \mathrm{eV}$ and then decreases at higher energy values. The values of $n$ at $\omega=0$ were found to be in the range of 1.75-2.2. In addition, the refractive index of the alloys slightly decreases in the energy range $0-2 \mathrm{eV}$ with the incorporation of $\mathrm{Zn}$ in the $\mathrm{CdO}$ system.

\subsection{Conclusion}

$\mathrm{Zn} @ \mathrm{CdO}$ alloyed nanostructured thin films were developed by sol-gel spin coating method on glass substrates. A quantitative comparison was made between experimental and DFT investigation of the role of $\mathrm{Zn}$ incorporation into the $\mathrm{CdO}$ system. From the XRD patterns, the crystallites sizes of films were estimated to be about $12-23 \mathrm{~nm}$. The lattice parameters of the $\mathrm{Zn} @ \mathrm{CdO}$ alloys change significantly with the increase in $\mathrm{Zn}$ doping concentrations. $1 \mathrm{wt} . \%$ and $2 \mathrm{wt} . \% \mathrm{Zn}$ doped samples show a reduction in the lattice parameters while sample doped with $3 \mathrm{wt} . \% \mathrm{Zn}$ reveals an increase in the lattice parameter. However, the overall lattice parameters values decrease with the incorporation of $\mathrm{Zn}$ into the $\mathrm{CdO}$ system. The optical band gap values were obtained from the Tauc plots in the range $\sim 2.07-2.60 \mathrm{eV}$, and were found to increase with increasing $\mathrm{Zn}$ doping concentration. The $\mathrm{Zn} @ \mathrm{CdO}$ cubic structures were optimized with $3.125 \%, 6.25 \%$, $12.5 \%$ and $25 \% \mathrm{Zn}$ concentration using $\mathrm{mBJ}-\mathrm{GGA}$ incorporated in the Wien2k package based on DFT. The calculated structural and optical parameters such as the lattice parameters, the band gap, the absorption index, the refractive index, the band edge and their variation with $\mathrm{Zn}$ incorporation into the $\mathrm{CdO}$ system reveals good agreement with 
the experimental findings. However, $12.5 \% \mathrm{Zn}$ doped samples show anomalous behavior which might be due to the structural changes in the $\mathrm{CdO}$ system. All the obtained results for the samples with this doping concentration indicate a significant variation in the properties of these samples and support the occurrence of a phase change in the $\mathrm{Zn} @ \mathrm{CdO}$ systems. To explore such effect in details, further experimental investigations of $\mathrm{CdO}$ nanostructured films with high $\mathrm{Zn}$ doping concentrations are required.

\section{Acknowledgement}

This research has been financially supported by Scientific Research Deanship at University of Ha'il-Saudi Arabia through project number RG-191242.

\section{References:}

[1] A. M. Mostafa, E. A. Mwafy, Optical Materials107 (2020)110124.

[2] S. Kose, F. Atay, V. Bilgin, I. Akyuz, Int. J. Green Energy 1 (2004) 353.

[3] R. K. Gupta, K. Ghosh, R. Patel, P. K. Kahol, J. Alloy. Comp. 509 (2011) 4146-4149.

[4] L. J. Heun, J. Korean Inst. Electr. Electron. Mater. Eng. 25 (2012) 632.

[5] Y. F. Sun, S. B. Liu, F. L. Meng, J. Y. Liu, Z. Jin, L. T. Kong, J. H. Liu, Sensors 12 (2012) 2610 .

[6] R. Saravanan, H. Shankar, T. Prakash, V. Narayanan, A. Stephen, Mater. Chem. Phys. 125 (2011) 277-280.

[7] R. Saravanan, F. Gracia, M. M. Khan, V. Poornima, V. K. Gupta, V. Narayanan, A. Stephen, J. Mol. Liq. 209 (2015) 374-380.

[8] B. Saha, R. Thapa, K. K. Chattopadhyay, Solid State Communications 145(2008)3337.

[9] R. Ferro, J. Rodríguez, Sol. Energy Mater. Sol. Cells 64 (2000) 363-370. 
[10] R. R. Salunkhe, C. D. Lokhande, Sens. Actuators B Chem. 129 (2008) 345-351.

[11] I. S. Yahia, G. F. Salem, J. Iqbal, F. Yakuphanoglu, Physica B 511 (2017) 54-60.

[12] V. Ganesh, S. AlFaify, Physica B: Condensed Matter 570 (2019) 58-65.

[13] R. Bairy, S. D. Kulkarni, M. S. Murari, Optics and Laser Technology 126 (2020) 106113.

[14] A. A. M. Farag, M. Cavas, F. Yakuphanoglu, Mater. Chem. Phys. 132 (2012) 550558.

[15] A. A. M. Farag, A. M. Aboraia, H. E. Ali, V. Ganesh, H. H. Hegazy, A. V. Soldatov, H. Y. Zahran, Y. Khairy, I. S. Yahia, Optical Materials 110(2020) 110458.

[16] S. Dugan, M. Mehmet Koç, B. Cos Kun, Journal of Molecular Structure 1202 (2020) 127235.

[17] M. Ravikumar, R. Chandramohan, K. Deva Arun Kumar, S. Valanarasu, A. Kathalingam, V. Ganesh, Mohd. Shkir, S. AlFaify, H. Algarni, Journal of Physics and Chemistry of Solids 118 (2018) 211-220.

[18] R. N. Bulakhe and C. D. Lokhande, AIP Conference Proceedings 503(2013)1536.

[19] S. J. Helen, S. Devadason, M. Haris, T. Mahalingam, Journal of Elec Materi 47(2018) 2439-2446.

[20] M. Thirumoorthi, J. T. Joseph Prakash, Journal of Asian Ceramic Societies 4(2016) $39-45$.

[21] S. A. Khan, S. Azam, F. Ali Shah, B. Amin, Optical Materials 47 (2015) 372-378.

[22] M. Durandurdu, Journal of Non-Crystalline Solids 412 (2015) 11-15.

[23] R. Miloua, F. Miloua, A. Arbaoui, Z. Kebbab, N. Benramdane, Solid State Communications 144 (2007) 5-9. 
[24] P. Blaha, K. Schwarz, G.K.H. Madsen, D. Kvasnicka, J. Luitz, WIEN2k, An Augmented Plane Wave Plus Local Orbitals Program for Calculating Crystal Properties, Vienna University of Technology, Vienna, Austria, 2001.

[25] W. Kohn, L. J. Sham, Phys. Rev. 140 (1965) 1133-1138.

[26] S. Cottenier, DFT and the Family of (L)APW-Methods: A Step-by-Step Introduction, University of Ghent, Belgium, 2004.

[27] V. G. Tyuterev, N. Vast, Comput. Mater. Sci. 38 (2006) 350-353.

[28] A. G. Imer, Superlattices Microstruct. 92 (2016) 278-284.

[29] R. J. Deokate, S.M. Pawar, A.V. Moholkar, V.S. Sawant, C.A. Pawar, C.H. Bhosale, K.Y. Rajpure, Appl. Surf. Sci. 254 (2008) 2187-2195.

[30] Cullity B D. Elements of X-ray diffraction. Reading (MA): Addison-Wesley; 1967.

[31] M. Banuprakash, B. Abhishek, H. Acharya, R. Bairy, S. Bhat, H. Vijeth, M. S. Murari, A. Jayarama, R. Pinto, Materials Today: Proceedings xxx (xxxx) xxx. https://doi.org/10.1016/j.matpr.2020.02.766.

[32] R. Danish, F. Ahmed, N. Arshi, M. S. Anwar, B. H. Koo, Transactions of Nonferrous Metals Society of China 24(2014) 152-156.

[33] Z. V. Popovic, G. Stanisic, D. Stojanovic, Phys. Stat. Sol. (b) 165(1991)109.

[34] M. Anitha, N. Anitha, K. Saravanakumar, I. Kulandaisamy, L. Amalraj, Appl. Phys. A 124(2018)561.

[35] J. Tauc, Amorphous and Liquid Semiconductors, Plenium Press, New York, 1974, p. 159.

[36] Bo Huang, Hsueh-Liang Chu, Moo-Chin Wang, Weng-Sing Hwang, Chao Liu, Xiujian Zhao, Journal of the Taiwan Institute of Chemical Engineers 80 (2017) 842-851. 
[37] G. Turguta, D. Tatar, Optik 145 (2017) 292-303.

[38] Mohd. Shkir, Z. R. Khan, Mohd. Anis, S. S. Shaikh, S. Al-Faify, Chinese Journal of Physics 63(2020) 51-62.

[39] Z. R. Khan, Mohd. Shkir, V. Ganesh, S. AlFaify, I. S. Yahia, H. Y. Zahran, Journal of Electronic Materials 47(2018) 5386-5395.

[40] M. S. Kim, K. G. Yim, J. S. Son, J. Y. Leem, Effects of Al concentration on structural and optical properties of Al-doped ZnO thin films, Bull. Korean Chem. Soc. 33 (2012) 1235-1241.

[41] B. J. Lee, J. Jeong, “A Study of Structural and Photoluminescence for Al-Doped CdO Thin Films” Journal of Spectroscopy, 2016 (2016) 6-5127348.

[42] K. Usharani, A. R. Balu, V. S. Nagarethinam, M. Suganya, Progress in Natural Science: Materials International 25 (2015) 251-257.

[43] M. Frumar, J. Jedelský, B. Frumarova, T. Wagner, M. Hrdlička, J. Non Cryst. Solids 326 (2003) 399-404.

[44] Mohd. Shkir, S. AlFaify, J. Mater. Res. 34 (16) (2019) 2765-2774.

[45] H. Ticha, L. Tichy, J. Optoelectron. Adv. Mater. 4 (2) (2002) 381-386.

[46] G. Yao, X. An, H. Lei, Y. Fu, W. Wu, Model. Numer. Simul. Mater. Sci. 3 (2013) 16.

[47] R. Asahi, A. Wang, J. R. Babcock, N. L. Edleman, A. W. Metz, M. A. Lane, V. P. Dravid, C. R. Kannewurf, A. J. Freeman, T. J. Marks, Thin Solid Films 411 (2002) 101105.

[48] A. Delin, P. Ravindran, O. Eriksson, J.M. Wills, Int. J. Quantum Chem. 69 (1998) 349-358. 
[49] M. Gandouzi, Z. R. Khan, A. S. Alshammari, Computational Materials Science 156 (2019) 346-353.

[50] M. Q. Cai, Z. Yin, M.S. Zhang, Appl. Phys. Lett. 83 (2003) 2805-2807.

[51] F. Wooten, Optical Properties of Solids, Academic, New York, 1972. 
Figures
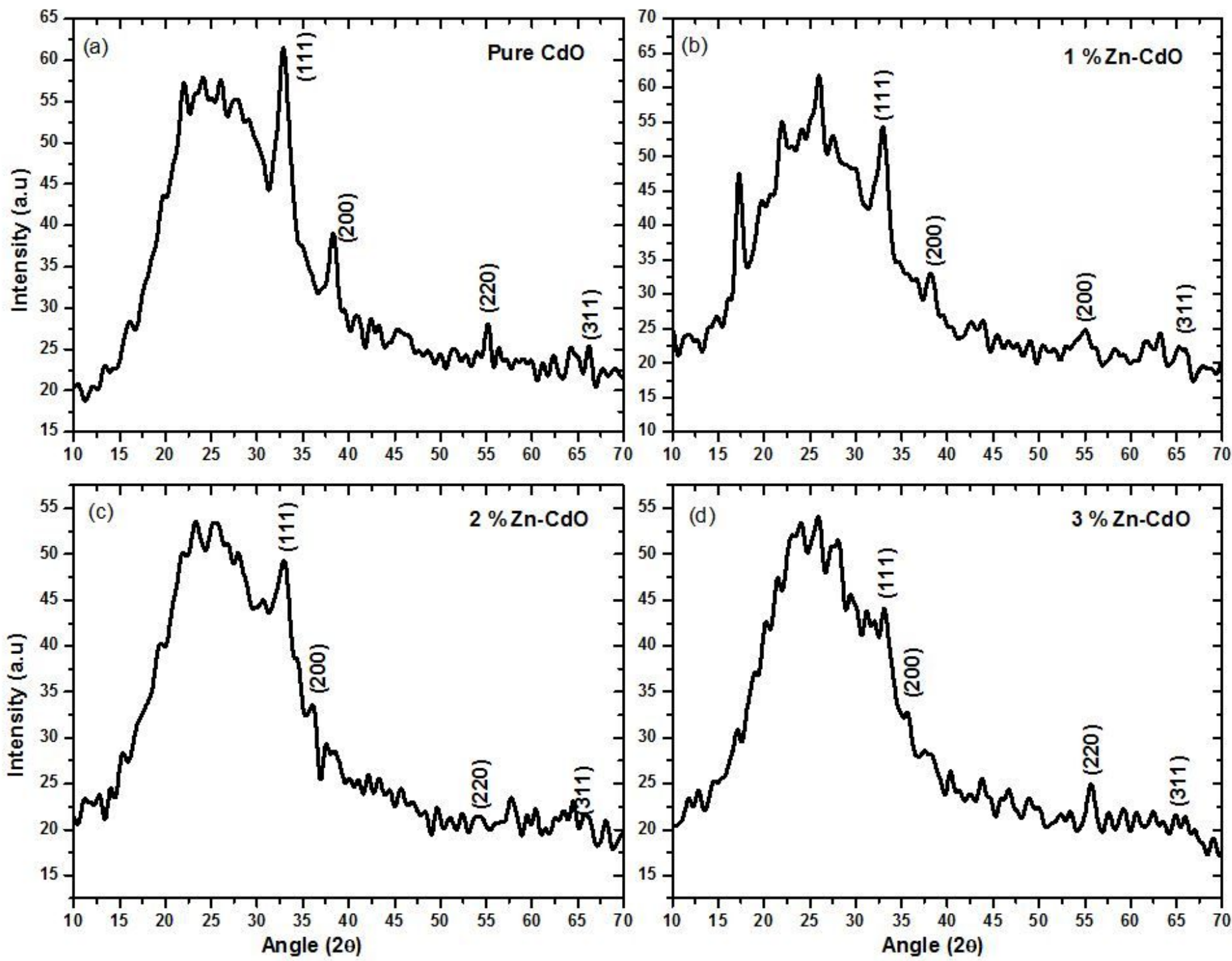

Figure 1

XRD patterns of Zn-CdO nanostructures thin films (a) Pure (b) 1 wt.\% Zn (c) 2 wt.\% Zn (d) 3 wt.\% Zn. 

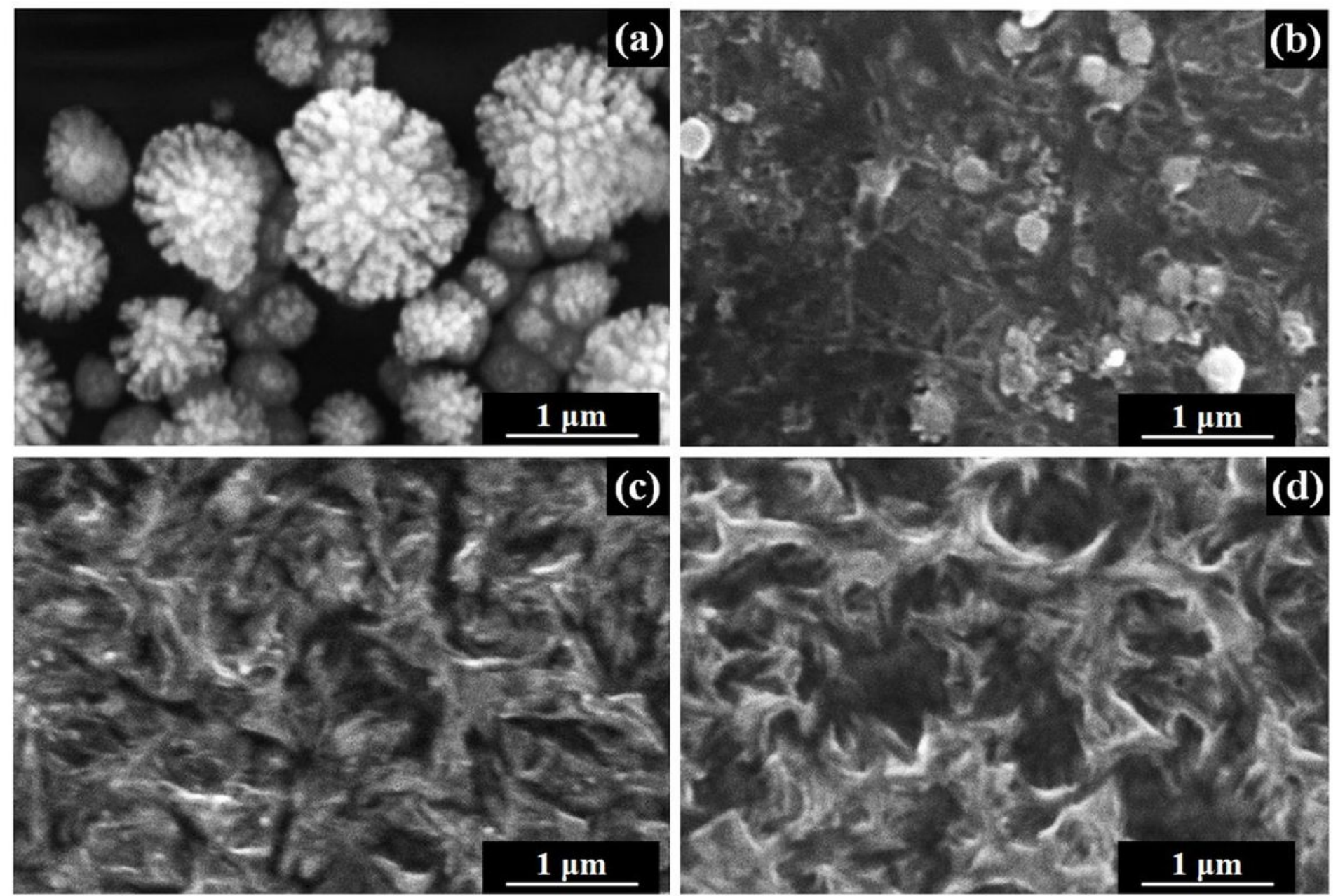

Figure 2

SEM images of Zn-CdO nanostructure thin films (a) Pure (b) 1 wt.\% Zn (c) 2 wt.\% Zn (d) 3 wt.\% Zn. 

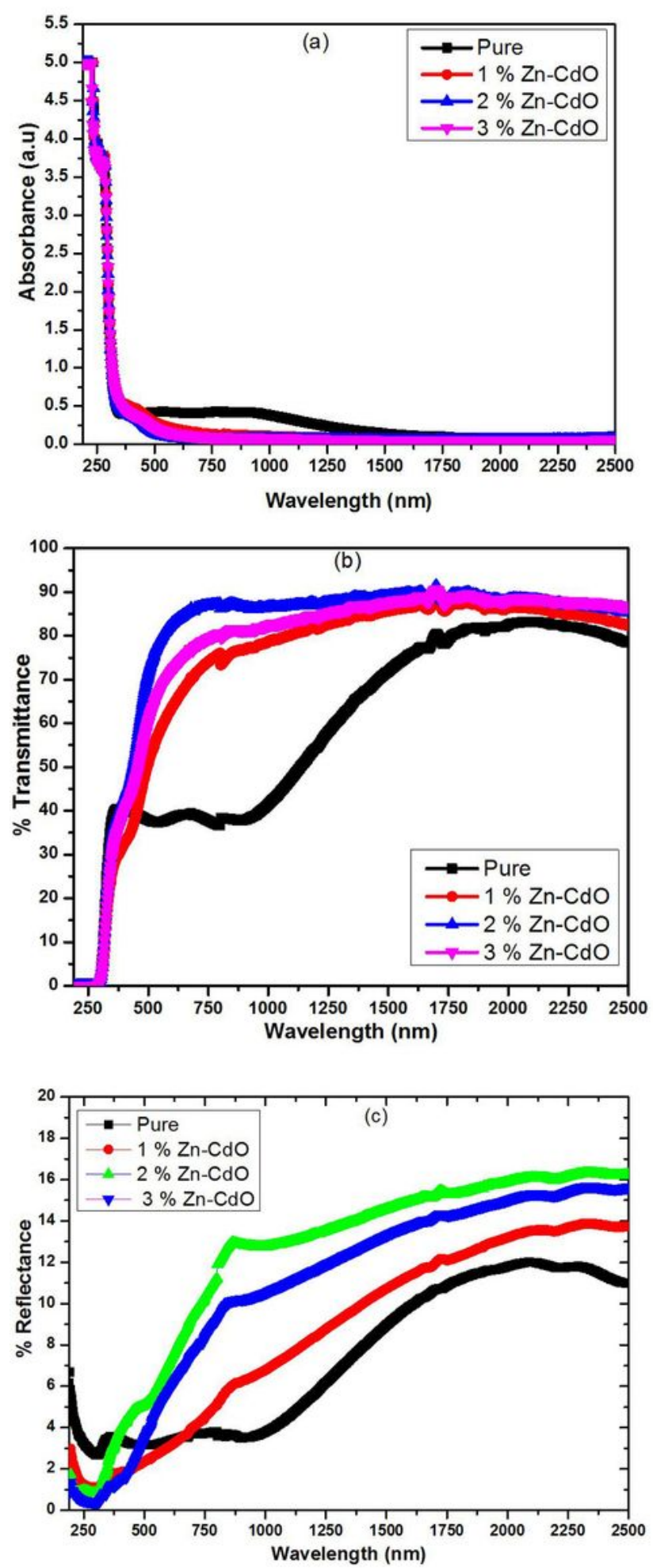

\section{Figure 3}

Uv-vis-nir spectra of Zn-CdO nanostructure thin films (a) Absorbance (b) Transmittance (c) Reflectance 

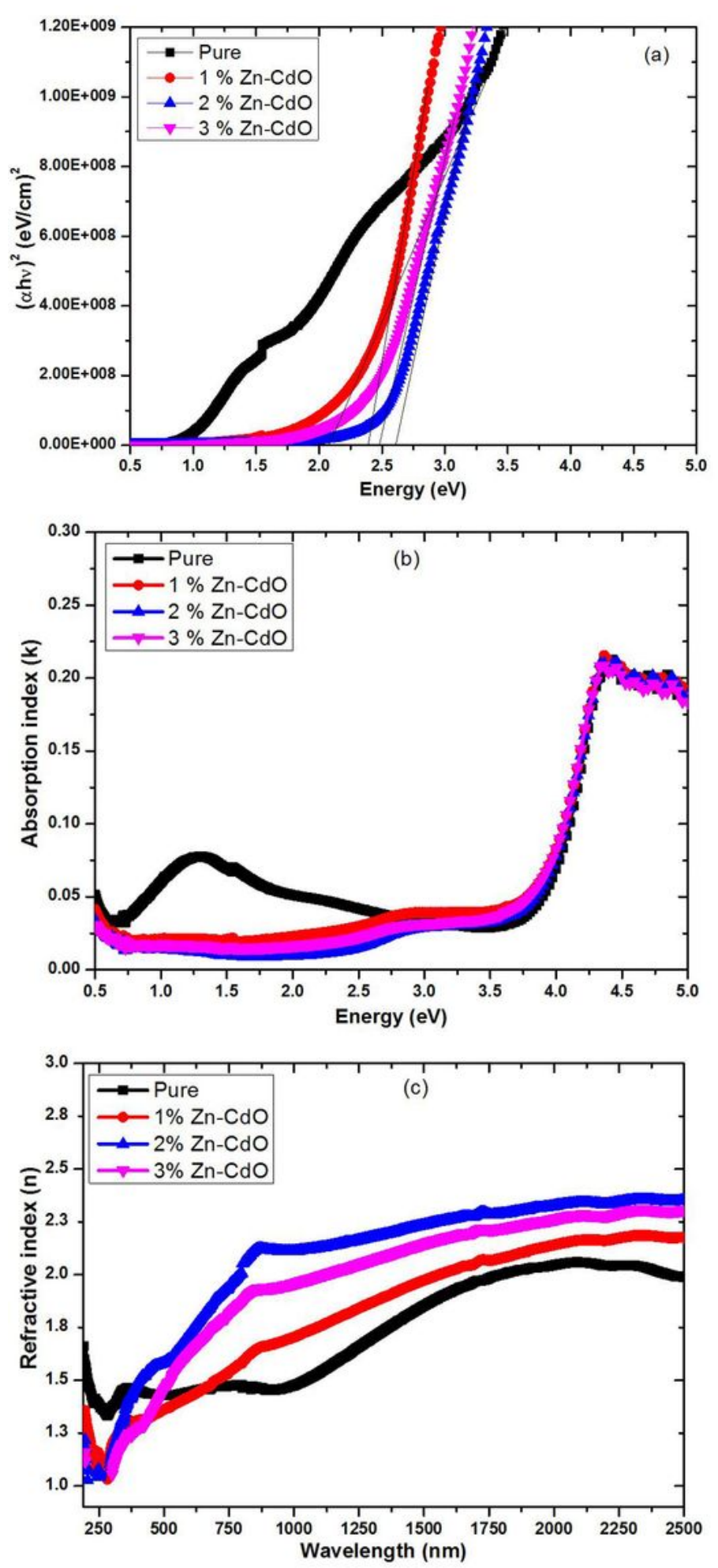

Figure 4

Tauc's plots and optical parameters of Zn-CdO nanostructure thin films (a) (ahv)2 vs. hv (b) Absorption index (k) (c) Refractive index (n). 

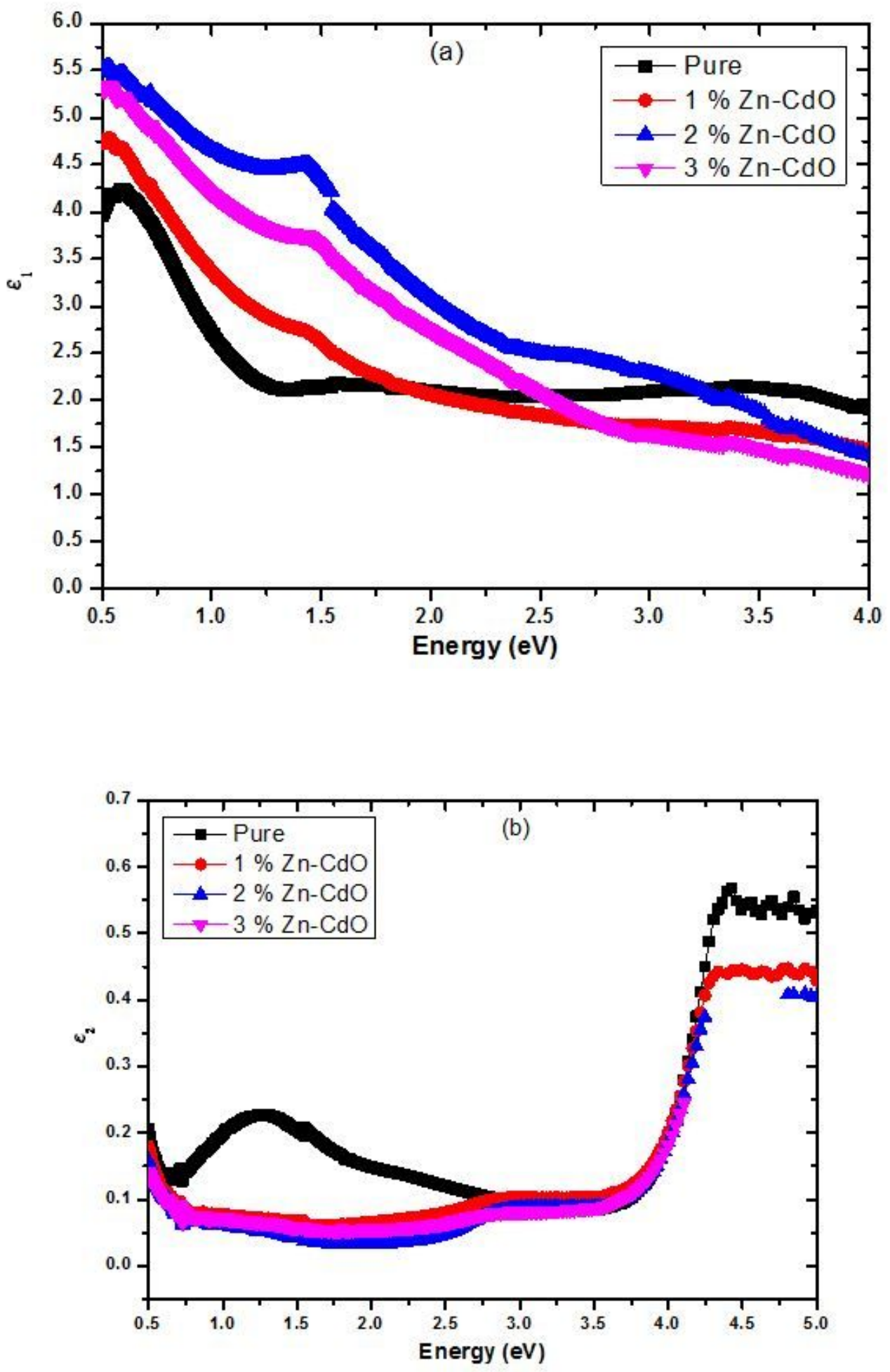

Figure 5

Optical dielectric constant of Zn-CdO nanostructure thin films (a) Real part ( $(\varepsilon 1)$ (b) Imaginary part $(\varepsilon 2)$. 

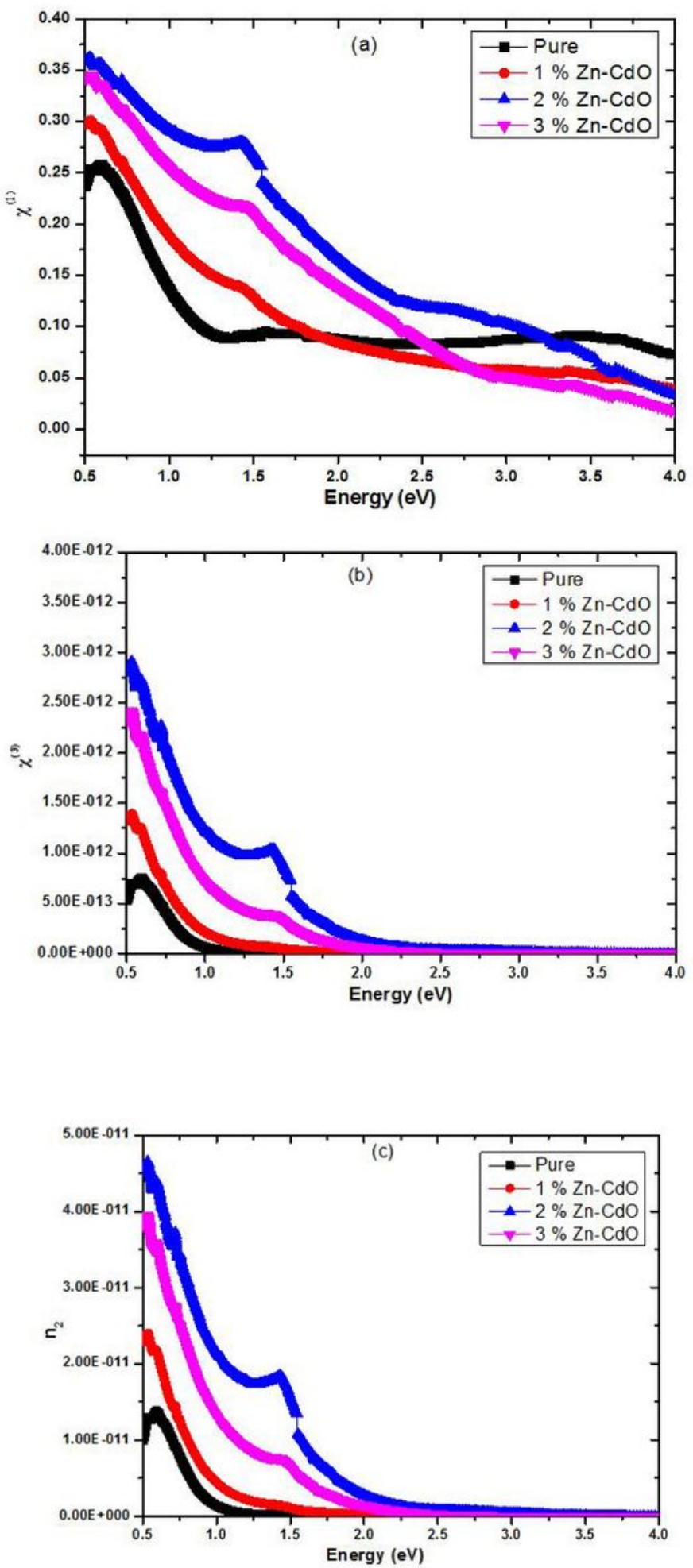

Figure 6

Third order nonlinear optical parameters of Zn-CdO nanostructures (a) $\chi(1)(b) \chi(3)$ (c) n2. 


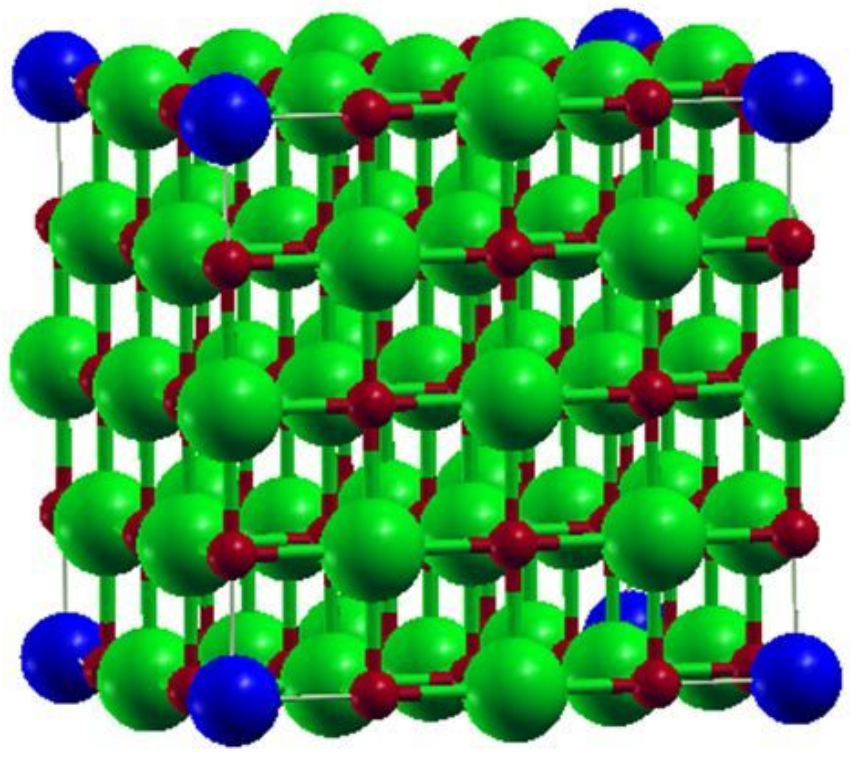

(a)

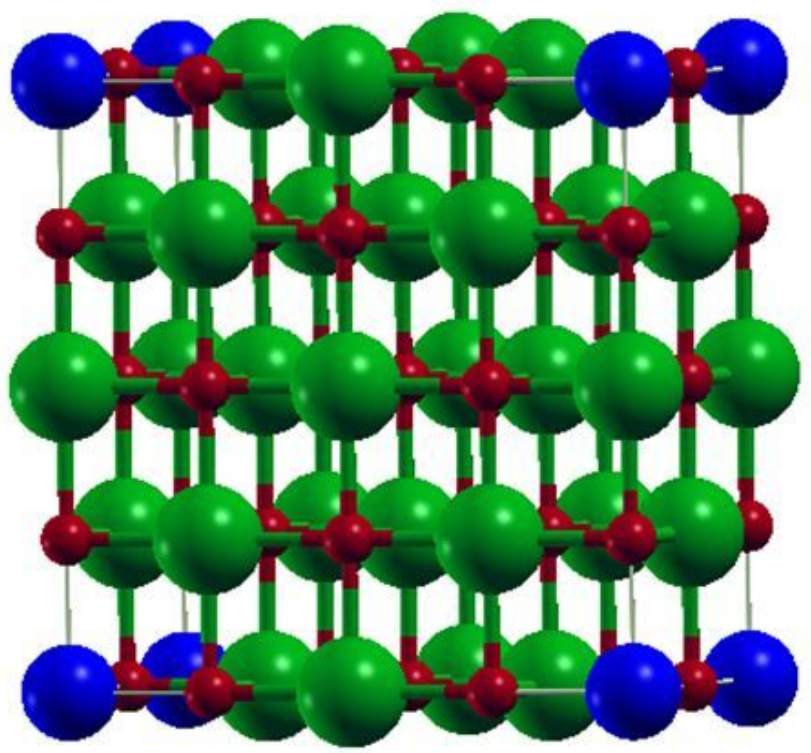

(b)

Figure 7

Structure of Cd1-xZnxO supercell; green, red and blue balls represent cadmium, oxygen and zinc atoms respectively (a) $3 \% \mathrm{Zn}$ (b) $6.25 \% \mathrm{Zn}$. 


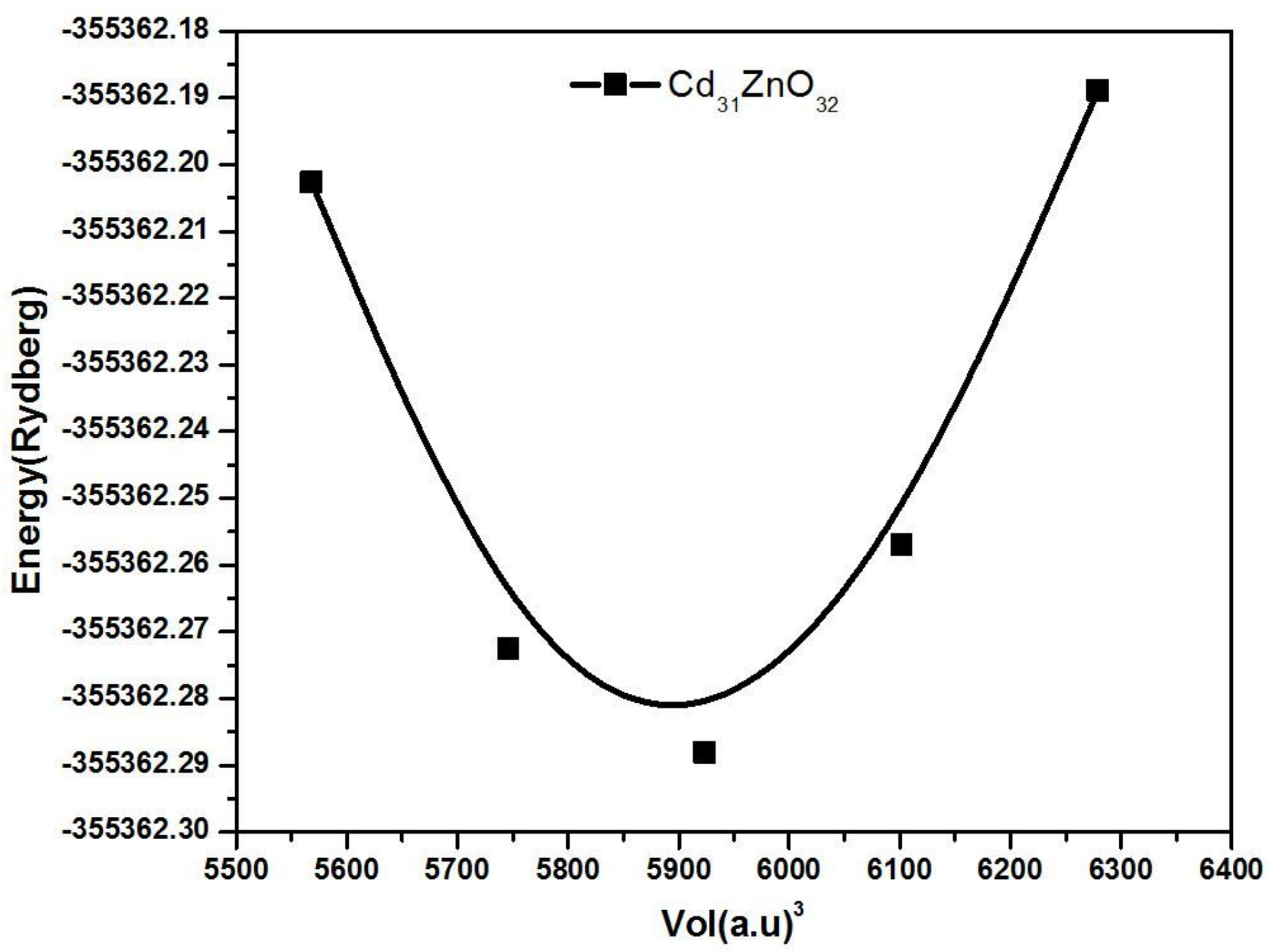

Figure 8

Variation of the total energy versus the volume for the $\mathrm{Cd} 1-\mathrm{x} \mathrm{ZnxO}$ alloys for $\mathrm{x}=3.125 \%$. 


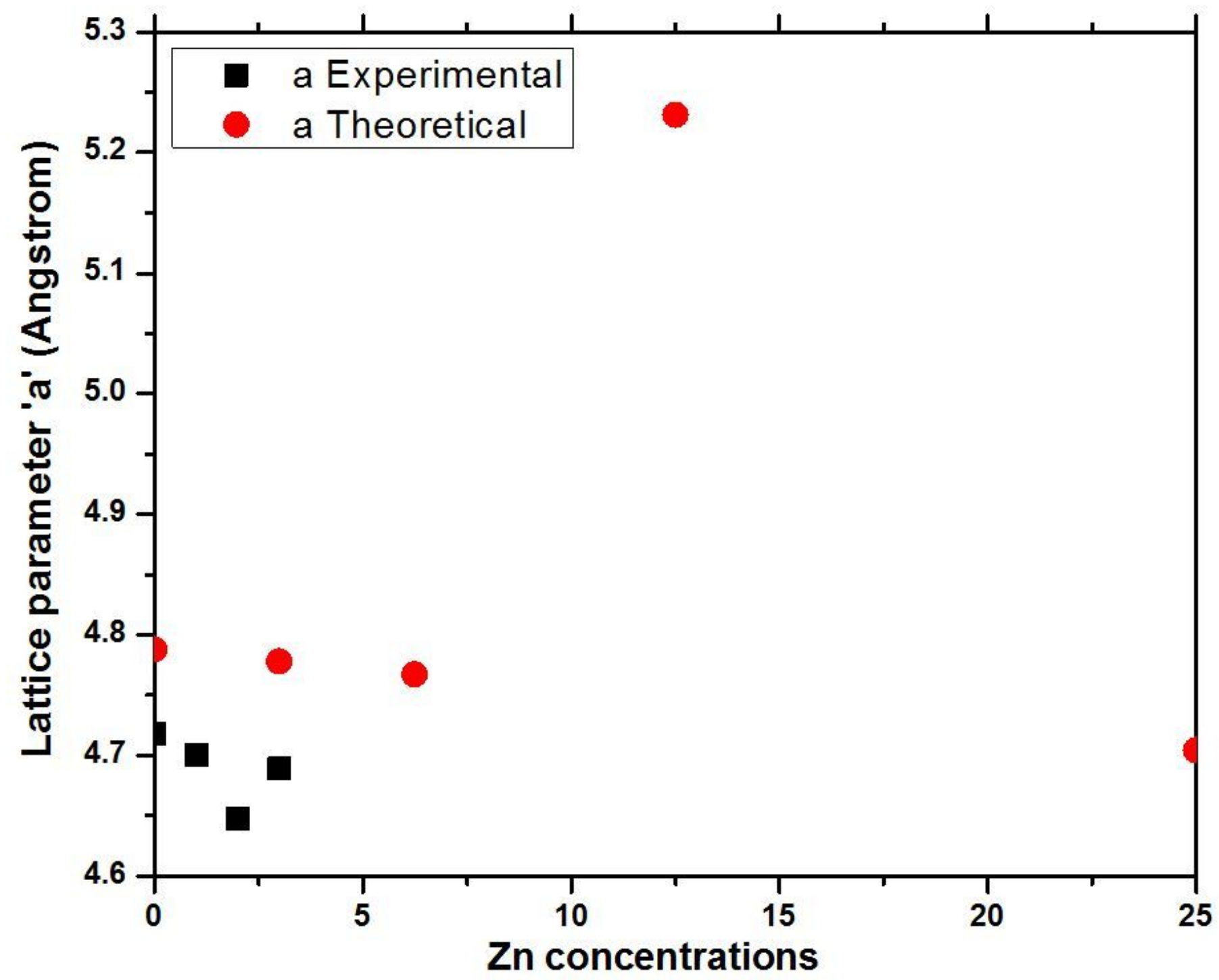

Figure 9

Variation of the experimental and calculated lattice parameters 'a' of Z@CdO alloys with different Zn concentrations. 

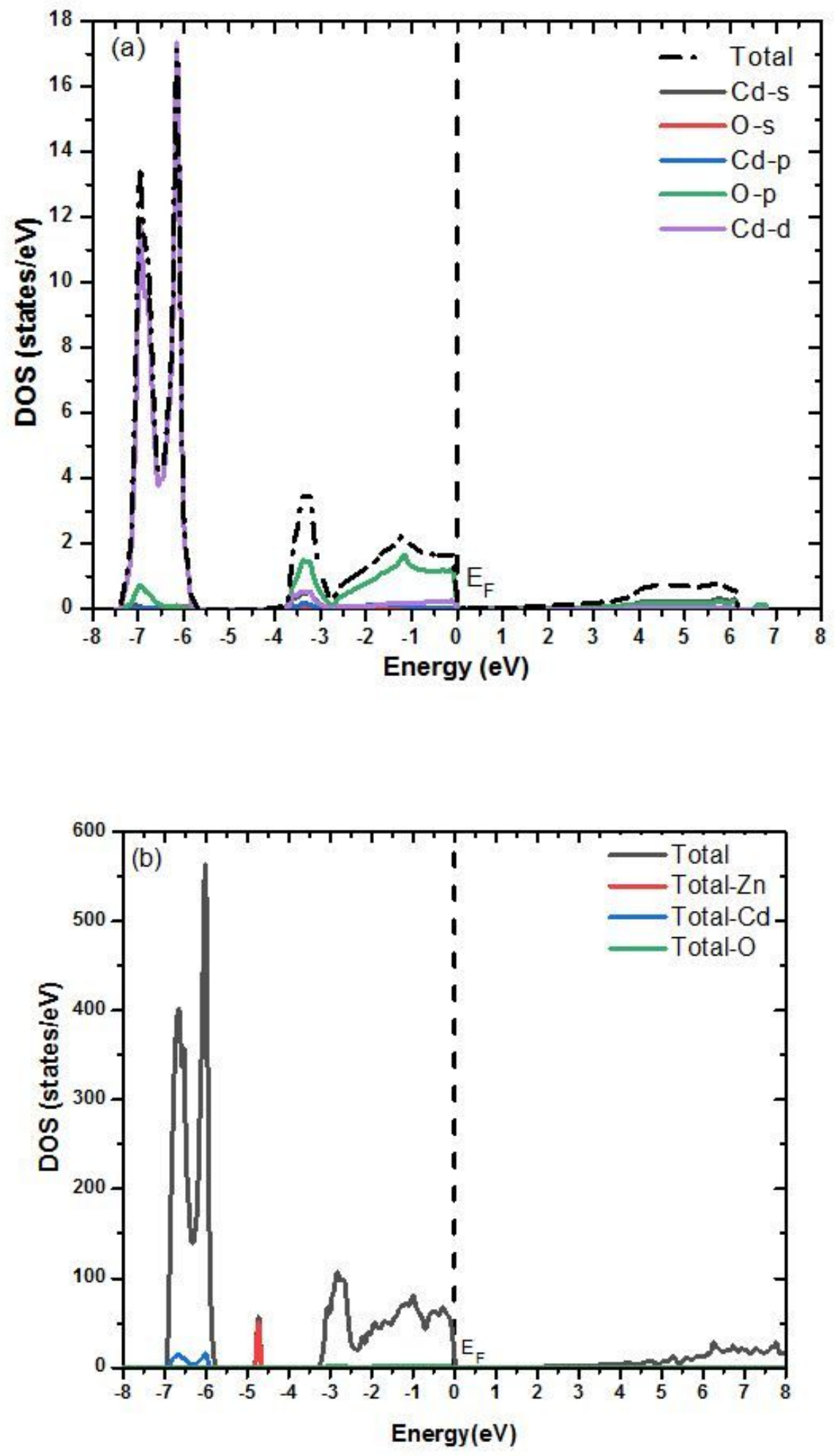

Figure 10

Total density of states of Cd1-xZnxO with different Zn doping concentrations (a) Pure CdO (b) $3 \% \mathrm{Zn}$ (Cd32Zn032). 

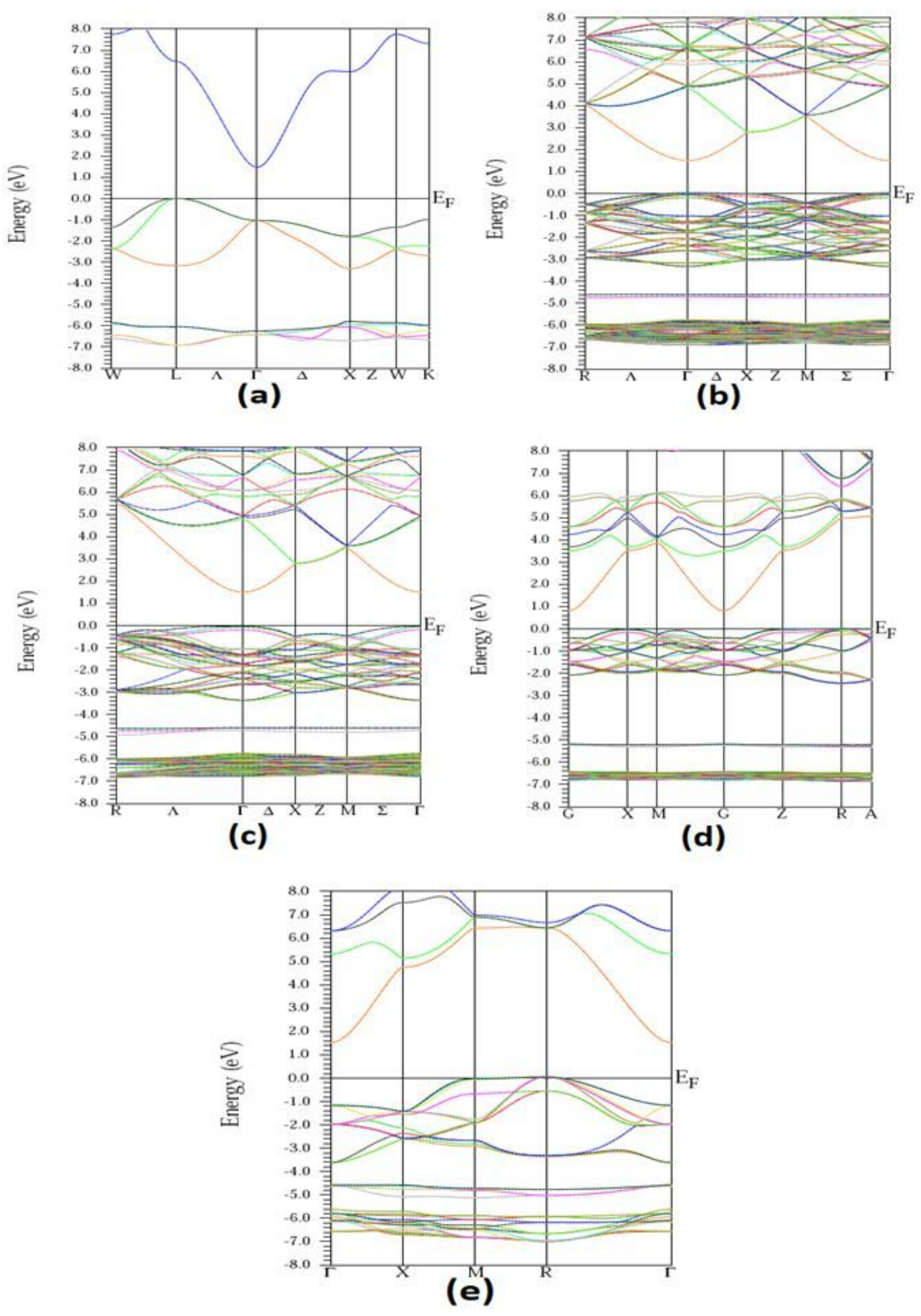

Figure 11

Band structure of Cd1-xZnxO with different Zn doping concentrations (a) Pure CdO (b) $3 \% \mathrm{Zn}$ (c) $6 \% \mathrm{Zn}$ (d) $12.5 \% \mathrm{Zn}(\mathrm{e}) 25 \% \mathrm{Zn}$. 

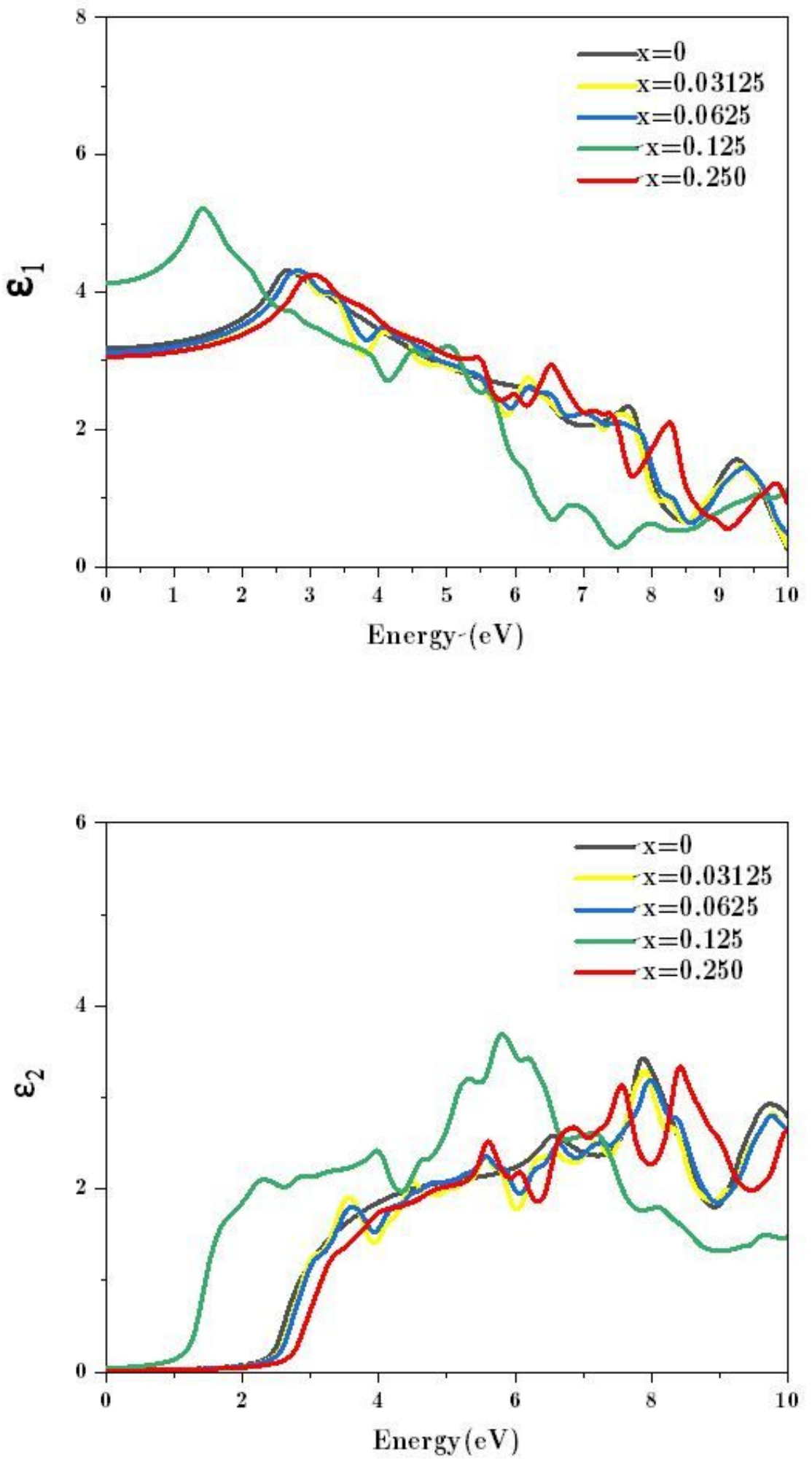

Figure 12

Calculated real and imaginary part of optical dielectric constant of $\mathrm{Cd1}-\mathrm{xZn \times O}$ with different $\mathrm{Zn}$ doping concentrations (a) Real part (b) Imaginary part. 

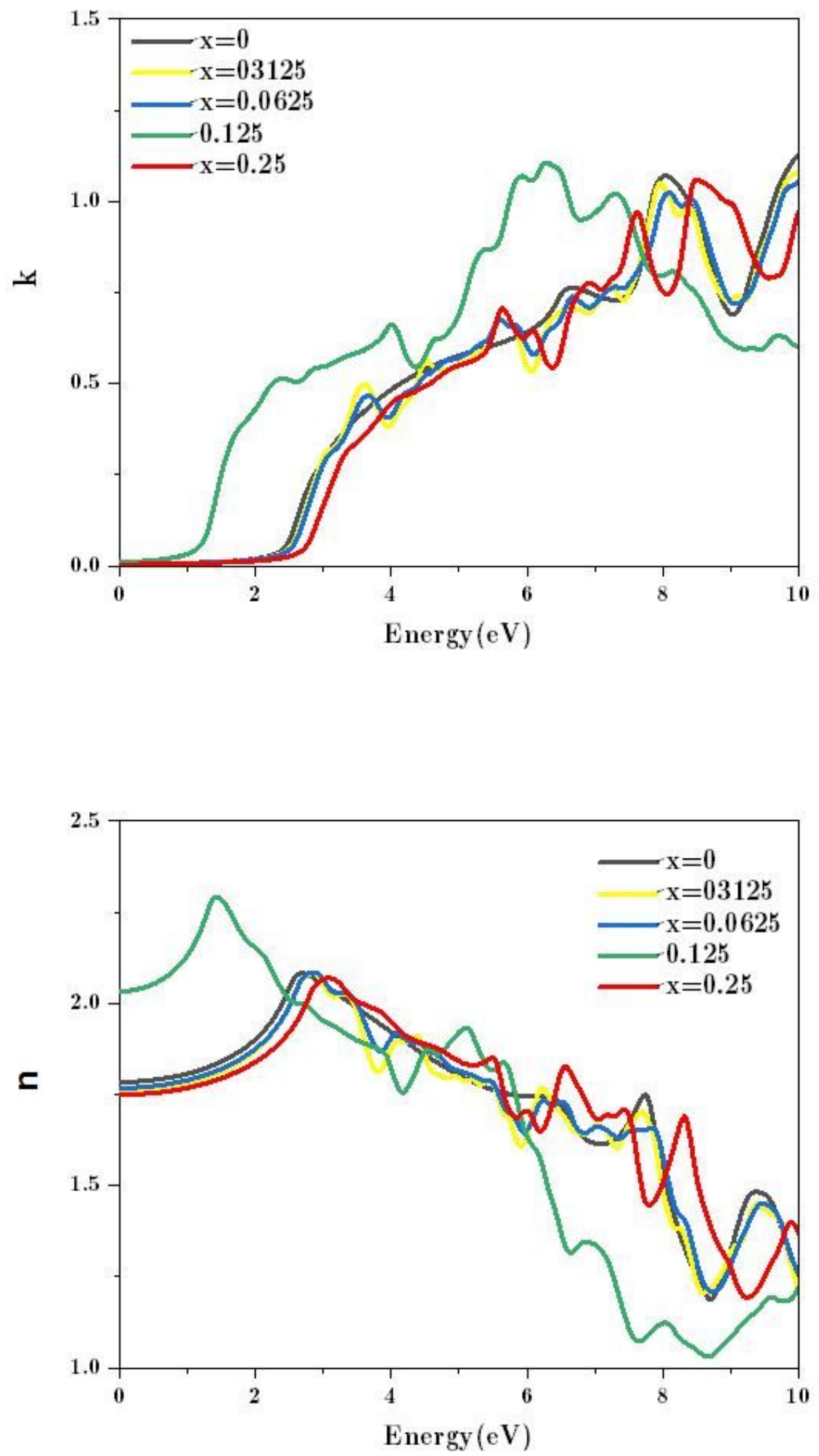

Figure 13

Calculated real and imaginary part of optical dielectric constant of $\mathrm{Cd1}-\mathrm{xZn \times O}$ with different $\mathrm{Zn}$ doping concentrations (a) Absorption index (k) (b) Refractive index (n). 